\title{
Modelo de asimilación y la tarea de las dos sillas para escisiones autocríticas
}

\section{The Assimilation Model and the two chair-work for self-critical splits}

\author{
Carlos López-Cavada y Rafael Jódar Anchía \\ Universidad Pontificia Comillas, España
}

\begin{abstract}
Resumen: En el siguiente artículo vamos a realizar una revisión de la teoría de la asimilación, adentrándonos con mayor profundidad en las características del constructo puentes de significado. La teoría de la asimilación es un modelo de cambio psicológico ante experiencias problemáticas.

Además, vamos a realizar un esfuerzo por poner en relación de forma teórica las fases del trabajo en la tarea de las dos sillas para escisiones autocríticas con los niveles de la Escala de Asimilación de Experiencias Problemáticas (APES). Así, pretendemos facilitar orientación acerca del trabajo con esta tarea en función del nivel de asimilación de la experiencia problemática. Palabras clave: modelo de asimilación; autocrítica; puentes de significado; cambio psicológico; tarea de las dos sillas.
\end{abstract}

\begin{abstract}
The paper below reviews the assimilation model, addressing in more depth the characteristics of the construct bridges of meaning. The theory of assimilation is a model of psychological change when problematic experiences are faced.

In addition, an effort will be made to theoretically relate the phases in the two chair work for self-critical splits to the levels of the Assimilation of Problematic Experiences Scale (APES). Thus, we intend to provide guidance on work with this task depending on the level of assimilation of the problematic experience.

Keywords: assimilation model; self-criticism; bridges of meaning; psychological change; two chair-work.
\end{abstract}

\section{Modelo de asimilación}

El modelo de asimilación es una teoría explicativa que busca dar cuenta de cómo funciona el cambio psicológico en cualquier tratamiento, por tanto, no es una teoría de tratamiento ni prescribe ninguna técnica en

\footnotetext{
Carlos López-Cavada es Psicólogo en Centro de Ejecución de Medidas Judiciales, Doctorando en la Universidad Pontificia Comillas de Madrid y Rafael Jódar Anchía es Psicólogo, Profesor Propio de la Universidad Pontificia Comillas de Madrid.

La correspondencia sobre este artículo debe enviarse al primer autor al e-mail: carloslopezcavada@gmail.com

(cc) BY-NC-ND Este es un artículo Open Access bajo la licencia CC BY-NC-ND.
} 
particular (Stiles, 2011). Esta teoría del cambio psicológico ha sido desarrollada en base a estudios de casos (por ejemplo, Brinegar, Salvi, Stiles, y Greenberg, 2006; Honnos-Webb, Stiles, Greenberg, y Goldman, 1998; Stiles et al, 1991, 2006). Asimismo, esta teoría bebe de aquellas conceptualizaciones teóricas sobre la personalidad organizada como una multiplicidad de yoes como la de Hermans (2004) o Rowan (1990) o el concepto de configuraciones de Mearns y Thorne (2003).

En consonancia a estas teorías de la multiplicidad del yo, la teoría de la asimilación plantea que la personalidad está compuesta por múltiples centros de experiencia a los que denomina voces (Honnos-Webb y Stiles, 1998; Osatuke, Gray, Glick, Stiles, y Barkham, 2004; Stiles, 1997, 1999). Estas voces se conforman a través de los rastros/huellas que dejan las experiencias anteriores.

Por experiencia, Stiles (2011) se refiere a todo aquello que se encuentra en la conciencia como percepciones, pensamientos, sentimientos, intenciones, acciones, etc. Stiles (1972, citado en Stiles, 2011) hipotetiza que la experiencia deja rastros físicos, siendo este el correlato fisiológico y las voces el psicológico.

Respecto a la información que cada experiencia deja como rastro, no es solo una percepción aislada o la idea de lo que ha sucedido, sino que permanece la actividad completa. Por ejemplo, ante el enfado de un padre por lo que valora como el mal comportamiento de un hijo, se registra la actitud facial, el tono de voz, el mensaje que envía, sus conductas motoras y el estado emocional que expresa, incluso más información.

La acumulación de experiencias construye a lo largo del tiempo voces internas con un funcionamiento coherente (Honos-Webb y Stiles, 1998). Esto sucede porque las huellas pueden reactivarse cuando la experiencia actual se parece a la original, aunque la similitud no sea completa. Estas experiencias similares se interconectan por lo que nuestros recuerdos, conocimientos, hábitos y habilidades son constelaciones de rastros interconectados. Además, las experiencias similares a las huellas se dirigen a la voz, la cual puede responder hablando o actuando, dejando ver que las voces tienen como cualidades el ser activas y poseer agencia (Mosher, Goldsmith, Stiles, y Greenberg, 2008).

El modelo de asimilación sugiere que cuando una persona habla, son las voces que representan sus experiencias las que hablan. Las voces pueden representar una persona significativa, un suceso, un trauma, una habilidad, una actividad o un rol adoptado en un momento determinado y se pueden configurar como un centro en torno al que se acumula los rastros de otras experiencias (Mosher et al., 2008). Cada una de estas voces proporciona recursos que permiten enfrentar las distintas situaciones de la vida.

Cuando una voz está activa, la persona toma una posición, es decir, una postura momentánea (cognitiva, afectiva y conductual) hacia una situación, persona o aspecto del sí mismo; la naturaleza de las voces se infiere al observar las posiciones que toma la persona (Stiles et al., 2006). Esta comunidad de voces que componen las diversas perspectivas de la persona es la caracterización de la personalidad.

Tal y como señalábamos anteriormente, las experiencias similares tienden a vincularse formando una comunidad de voces en la que nace una voz dominante que sería la "representante" de la comunidad (Mosher et al., 2008). Esta voz es la que la persona experimenta como el centro de su experiencia, dicho de otra manera, su personalidad o sí mismo habitual (Mosher et al., 2008; Stiles, 2011).

Las comunidades de voces tienen la cualidad de ser autoorganizadas: emergen y actúan en función de las respuestas que requiera cada circunstancia (Stiles, 2011). Así, una circunstancia dada provocará la respuesta de la voz cuyos rastros se parezcan a dicha circunstancia. Cuando la voz responde, se convierte en el centro de la experiencia. Consecuencia de todo esto, la voz que emerge tiende a ser apropiada para la persona y la situación. De esta forma, mis habilidades de psicólogo se activarán con menos probabilidad mientras estoy conduciendo que cuando estoy en el despacho. De otro lado, la voz de mis habilidades de conducción será la que tome un papel central mientras me dirijo de casa al trabajo.

\section{¿Qué sucede cuando una voz es discordante con la comunidad de voces?}

Generalmente, la existencia de una voz problemática será la que conduzca a las personas a una sala de terapia (Stiles, 2011).

Esto es, cuando se dan experiencias dolorosas, sean físicas o psicológicas, que son problemáticas en relación 
a la comunidad de voces, estas no son asimiladas debido a su incompatibilidad o conflictividad (Mosher et al., 2008; Stiles, 1997, 2011). Como ejemplo de estas voces problemáticas podemos encontrar experiencias traumáticas o la vivencia de relaciones primarias destructivas (Stiles, 2011).

Las voces problemáticas generan un afecto negativo, favorecen la aparición de angustia emocional, por ello, se evitan o se intentan mantener a raya (Stiles, Osatuke, Glick, y Mackay, 2004). Su activación se da por circunstancias externas. Por lo general, la comunidad intentará distorsionar o evitar activamente la voz disonante y, de esta manera, lograr que esta no esté disponible y se pueda reducir o suprimir la angustia (Stiles, 1992, 2002).

Por tanto, la confrontación de voces disonantes generan un efecto en el afecto (Stiles et al., 2004), es decir, una respuesta orgánica automática (Stiles, 2011). El afecto puede reflejar una activación excesiva o insuficiente, de modo que una experiencia problemática por su inconsistencia con el centro de la experiencia actual generará una sobreactivación con afecto negativo. Sin embargo, en una experiencia congruente, el afecto es positivo o neutral (Stiles, 2011). Por tanto, en la línea de lo expresado por Rogers (1959) el afecto puede tener una importante función de valoración y señalización (Stiles, 2011).

Stiles (1972, citado en Stiles, 2011) indica que la sobreactivación que se debe a un intenso afecto negativo produce una supresión global equilibrada en todas las trazas. El equilibrio dinámico entre la sobreactivación de trazas específicas y la supresión global conduce a favorecer la actividad en uno solo de los conjuntos de trazas (Stiles, 2011). Si el afecto es intenso una de las voces, en general la problemática, tiende a suprimirse. En caso de que sea la voz dominante se puede experimentar la voz problemática como un flasback o como un cambio de estado (Stiles, 2011). Como resultado de la supresión de una de las voces es que estas permanecen disociadas al no existir contacto y no poder extender puentes entre ellas (Stiles, 2011).

Si la incompatibilidad es respecto a algo menos intenso, el afecto es intenso pero su duración más breve debido a que la voz se evita de forma rápida (Stiles, 2011). No obstante, cuando se mantiene activada se puede observar la voz a través del llanto o de otra expresión intensa (Stiles et al., 2004).

Otras manifestaciones de las voces problemáticas pueden ser las parapraxis, expresiones extrañas u otras sutilezas del lenguaje (Stiles, 2011).

\section{¿De qué manera se puede superar esta disociación y el malestar asociado a la existencia de voces discordantes?}

La teoría de la asimilación propone el establecimiento de puentes de significado entre ambas voces (Brinegar et al., 2006; Mosher et al., 2008; Osatuke et al., 2005; Stiles, 2011). Estos puentes de significado están compuestos por un signo o por un conjunto de signos. Los signos son palabras, frases, una narrativa, imágenes, gestos, etc. Tienen la característica de ser observables y dar acceso a las mentes de las personas puesto que refieren y transmite la experiencia de la persona que los genera (Stiles, 2011). Los signos tienen un significado similar para el emisor (autor) y receptor (destinatario).

De ahí, la importancia de atender a las historias de los pacientes, a las metáforas que emplean y las imágenes que producen, así como atender a sus gestos y otras acciones que contengan un significado simbólico.

En cuanto a la relación del signo y el significado hay que explicar lo siguiente (Stiles, 1999, 2011):

- Mientras que el significado es experiencial (de la experiencia de la persona) y privado, los signos son observables para el receptor.

- El significado no existe con independencia del signo.

- Cada vez que se emplea un signo, el significado cambia su uso. Esto tiene que ver con el hecho que cada vez que se emplea un signo se está incorporando nueva experiencia; antes el masculino en inglés se refería a ambos sexos, en el momento actual, sólo refiere a lo masculino pero conserva lo neutro, con el consiguiente debate sobre el sexismo. Sin embargo, es necesario que exista una continuidad sustancial (historicidad) en el significado del signo para que las personas entiendan lo que están diciendo. De aquí también se puede entender que al inicio de la construcción de un puente de significado, el receptor del puente de significado solo obtiene una impresión vaga. 
- Como el significado del signo es similar en lugar de idéntico, nunca llegamos a entendernos perfectamente. En el contexto concreto de la terapia, a pesar de adoptar una posición plenamente empática, nunca se va a captar plenamente el significado del signo para el cliente. Además, sucederá que conforme se avance en la terapia una expresión acerca de una experiencia irá añadiendo los nuevos significados que adquiera del proceso de terapéutico.

Por tanto, para construir un puente de significado sirve cualquier construcción semiótica que se dirige entre y hacia las distintas experiencias (Stiles, 2011). Por ejemplo, si yo hablo de la parte de mí que desprecio se puede referir a una parte del sí mismo sufriente, débil, acosada por otra que critica y que se manifiesta a través de actuaciones de pérdida de control. La construcción la parte de mí que desprecio es un puente que da acceso mutuo a las experiencias de cada una de las voces, la sufriente y la crítica. Un puente de significado se convierte en mutuamente válido en la medida en la que el emisor también adapta sus herramientas semióticas para adaptarse a sus destinatarios, motivo por el cual, los puentes de significado son co-construidos con el fin de que sean comprensibles y compartidos.

Los puentes de significados interpersonales se pueden emplear como puentes intrapersonales. De esta manera, los puentes construidos durante las sesiones terapéuticas se pueden trasladar a la relación intrapersonal. Así, la simbolización de la experiencia, la identificación de pensamientos automáticos negativos, atender a la sensación sentida permite formar puentes semióticos con las voces problemáticas (Stiles, 2011), que se tornaron así por una autonarrativa que la excluía de la comunidad de voces (Ribeiro, Bento, Salgado, Stiles, y Gonçalves, 2011).

Con todo esto, podemos señalar que los puentes de significado intrapersonales, es decir, entre las distintas voces de la comunidad, permiten que estas trabajen como una comunidad muy unida, con acceso a los recursos de cada una de las voces. Esto se da en parte porque el signo o signos que constituyen el puente de significado hacen que cosas distintas se conviertan en similares. También influye el hecho de que los signos parecen hacer presente lo que significan (Leiman, 2002).

Cuando las personas expresan las posiciones de los diferentes lados de la ambivalencia, como si fuese una conversación (Brinegar et al., 2006) es el momento en el que se establecen los puentes (Mosher et al., 2008; Stiles, 1999, 2011). Si la elección de los signos (palabras, imágenes...) es la adecuada, se genera una sensación satisfactoria de congruencia, de sentimiento comprendido; esto se debe a la expresión clara de la experiencia.

Por tanto, debido a que las voces problemáticas generan sentimientos angustiantes, parte del trabajo terapéutico implica la resolución de estados emocionales dolorosos o displacenteros para poder establecer los puentes de significado. El puente se construirá si las experiencias se mantienen en el foco de atención el tiempo suficiente para construir puentes hacia el afecto negativo. A su vez, el afecto se volverá menos negativo en la medida que el puente se vaya construyendo (Stiles, 2011).

En función de la corriente terapéutica pueden existir distintas técnicas (ejemplo, experienciar durante la sesión o in vivo) y diferentes tipos de puentes (por ejemplo, un enfoque centrado en el cliente dirigirá el foco a que las voces en conflicto descubran sus propios puentes; los cognitivos darán puentes racionales; o un psicodinámico ayudará a establecer puentes en relación a la historia y a lo interpersonal de cada persona) (Stiles, 2011).

\section{¿Cómo se enlazan los rastros?}

Las trazas de experiencia se pueden enlazar si se mantienen en la conciencia el suficiente tiempo para que se formen enlaces junto a otras experiencias; los principales mecanismos son los de contigüidad y similitud (Stiles, 2011).

La contigüidad implica que si una experiencia deja un rastro que permite que se reactive ante determinadas circunstancias, el experimentar cosas que ocurren al mismo tiempo puede hacer que se vinculen y sean reactivadas al mismo tiempo. Por otro lado, la similitud implica también a la contigüidad, si cosas similares a la original activan su rastro, se da contigüidad entre los nuevos eventos que reexperimentarán de manera conjunta. Stiles (2011) explica que si con un paciente se está trabajando el autorrechazo, se le puede preguntar 
si una experiencia determinada es otra forma de su autorrechazo para que la persona pueda tomar consciencia de los momentos previos en la situación actual. Esto es, los rastros de la nueva experiencia incluyen rastros de experiencias antiguas y similares, motivo por el cual parte de la preocupación actual es el recuerdo de momentos previos.

\section{La Escala de Asimilación de Experiencias Problemáticas (APES)}

Una voz discordante puede variar en función del nivel de consciencia que la persona tiene sobre ella. Cuando se da un proceso terapéutico es esperable que cada vez haya un mayor nivel de consciencia de la voz discordante, así como un proceso de asimilación y acomodación con la voz dominante. Dentro del modelo de asimilación se han descrito una serie de estadios que describen en qué nivel de consciencia (de menor a mayor) se encuentra la experiencia suprimida (Stiles et al., 1991). Estos estadios/niveles se encuentran recogidos en la Escala de Asimilación de Experiencias Problemáticas (APES; Stiles et al., 1991).

Los autores (Stiles et al., 1991) señalan que una persona puede acudir a sesión en cualquier nivel de asimilación de la experiencia, es decir, el nivel de consciencia de las diferentes experiencias puede variar cuando se inicia un proceso terapéutico.

La escala cuenta con ocho niveles que van de 0 a 7 , sin embargo este intervalo tiene un carácter cualitativo, no cuantitativo. Por ello, se pueden dar puntuaciones intermedias como un intento de dotar de más precisión y descripción al proceso (Stiles et al., 1991). Además permite apreciar que los cambios en la asimilación no son progresivos, sino que sucede en picos (Caro, 2003). Los niveles son los siguientes:

APES 0. Supresión/disociación. El contenido del problema no está formado y el paciente no es consciente del mismo. Debido a que la evitación del problema es exitosa, no existe angustia o esta es mínima.

APES 1. Pensamientos no deseados/ evitación. Hay presencia de pensamientos angustiantes sobre los que se prefiere no pensar. La presencia de los problemas tiene lugar de forma externa (el terapeuta o una circunstancia dada). Debido a esta evitación se hace mucho más manifiesto el afecto negativo (fuertes sentimientos de ansiedad, miedo, ira y tristeza) que el contenido.

APES 2. Reconocimiento vago/surgimiento. En este punto ya existe un reconocimiento de la experiencia problemática, así como una descripción precisa de los pensamientos angustiantes asociados. Sin embargo, el problema no está formulado con claridad. El polo afectivo refleja dolor psicológico agudo y pánico asociado a pensamientos y experiencias problemáticas.

APES 3. Enunciar el problema/clarificación. En este nivel se puede trabajar sobre un problema más conformado, además, el afecto aún negativo es más manejable.

APES 4. Comprensión/insight. La formulación del problema es más amplia, como dentro de un esquema en la que se entienden y enlazan las dificultades de manera clara. Si bien el reconocimiento puede evocar estados emocionales desagradables también puede surgir curiosidad o cierto agrado por lo que está emergiendo.

APES 5. Aplicación/elaboración. Una vez se entiende el esquema del problema, se puede trabajar con él, buscando la solución del mismo. El tono afectivo es positivo, más optimista.

APES 6. Solución del problema. En este nivel, se logra la solución de forma específica, por lo que el afecto es más neutral al estar paliado este problema. Pueden aparecer sentimientos de satisfacción y orgullo.

APES 7. Dominio. Se da una generalización a otras situaciones. Comienza a suceder de manera automático, por lo que el afecto es neutral, forma parte de la cotidianeidad.

\section{La tarea de las dos sillas y la asimilación de las voces}

En el marco de la Terapia Focalizada en la Emoción (TFE) también existe una conceptualización de la personalidad como una pluralidad de yoes. En este caso, Leslie S. Greenberg (Greenberg, Rice, y Elliott, 1996; Cooper, Mearns, Stiles, Warner, y Elliott, 2004) emplea el término autoorganización. 
Desde este modelo emplean tareas experienciales para poder trabajar con las escisiones del yo; en este caso, cada una de estas escisiones representaría las voces de la teoría de la asimilación.

Leslie S. Greenberg y su equipo adaptan estas tareas de la terapia Gestalt (Elliott, Watson, Goldman y Greenberg, 2004; Greenberg et al., 1996), que a su vez había tomado estas intervenciones del psicodrama de Jacob Levy Moreno (Ramírez, 1998).

En concreto, Fritz Perls, padre de la terapia gestáltica había recibido formación en el Beacon Sanatorium, abierto por J. L. Moreno en 1936, quien venía desarrollando la técnica de la inversión de roles desde 19211923 en el Teatro de la Espontaneidad de Viena (Ramírez, 1998). El objetivo de esta técnica es facilitar el crecimiento personal mediante el alivio de sentimientos acumulados, proporcionando insight y desarrollando conductas nuevas y más efectivas. Para ello, el terapeuta facilita el cambio sugiriendo técnicas/tareas que intensifiquen sentimientos, recreen situaciones pasadas y permitan lograr una mayor conciencia de los conflictos (Ramírez, 1998). Una de estas tareas el diálogo de las dos sillas.

Greenberg (Elliot et al., 2004; Greenberg et al., 1996) dirigen la tarea de la silla vacía para trabajar asuntos no resueltos con personas significativas. Además, para trabajar con las voces críticas (yo crítico o crítico interno) emplean y sistematizan la tarea de las dos sillas (Greenberg et al., 1996). En este caso, nos encontramos con una voz crítica que contiene las normas y valores, es decir, los deberías, que se encuentran separados y en conflicto con las reacciones emocionales y deseos organísmicos (Greenberg, 1984, citado en Greenberg et al., 1996). En estas escisiones hay un fuerte componente autoevaluador que genera malestar. En este sentido aunque cada voz está compuesta por sus conjuntos de esquemas de pensamientos, sentimientos, necesidades y creencias, la voz crítica presenta un procesamiento más conceptual, mientras que la voz que expresa sus deseos y sufre la crítica presenta un procesamiento más vivencial (voz experimentador), por ello, está cargada de reacciones y necesidades afectivas (Greenberg et al., 1996).

El objetivo de esta tarea consiste en lograr una suavización de la crítica de la persona mediante un diálogo creativo que permite conectar estas dos voces disociadas, a través de la expresión de las necesidades, sentimientos y deseos que configuran cada una de ellas. En términos del modelo de asimilación explicamos el objetivo de la tarea de la siguiente forma: el diálogo que tiene lugar a través de la expresión de cada una de las voces, en cada una de las sillas, permite establecer puentes de significado gracias a la mayor comprensión existente de la organización de cada voz, es decir, la voz crítica y la voz del experienciador.

A continuación vamos a exponer las distintas etapas de resolución de la tarea de las dos sillas (Greenberg et al., 1996) en relación a la secuencia de asimilación de las experiencias problemáticas (Stiles, Honos-Webb, y Lani, 1999):

En primer lugar (APES 0. Supresión/disociación), la persona suele presentar una escasa conciencia de la presencia de aspectos autoevaluativos o autocoercitivos. Como la percepción del conflicto es escasa, el nivel de afecto es bajo puesto que la voz problemática está disociada. La persona puede tratar de evitar (de forma inconsciente) hablar de un tema. En esta fase, es importante iniciar una relación basada en la empatía que permita explorar (empáticamente) cual es la situación de la persona, es decir, el motivo que le trae a consulta.

Posteriormente (APES 1. Pensamientos no deseados/ evitación) persiste la ausencia de conciencia del conflicto porque es evitado. Sin embargo, como se dan situaciones que hacen aflorar malestar la persona puede comenzar con verbalizaciones que indican un conflicto que trata de ser evitado activamente; esto se puede comenzar a apreciar a través de conflictos decisionales. En sesión, la tarea del terapeuta es identificar marcadores de conflicto que en primera instancia son sutiles, como por ejemplo, sensaciones corporales poco claras que reflejan el conflicto subyacente. También pueden aparecer autointerrupciones sobre las que habría que trabajar con su tarea específica (para ver más, Greenberg et al., 1996).

Asimismo, las personas pueden expresar sentimientos de ansiedad, enfado, de bloqueo y de confusión y dificultad para tomar decisiones. Un sentimiento más específico que le sirven al terapeuta como marcador de la presencia de una escisión autocrítica es el relacionado con la vergüenza, que puede señalar el miedo a ser visto por el sí mismo como inferior a los ojos de lo demás, como posible objeto de burla o alguien repugnante; por tanto, de manera implícita señala que existe una autoevaluación en la que hay una atribución de aversión. 
Por ello, el terapeuta debe continuar manteniendo una escucha activa para comenzar a facilitar la toma de consciencia del problema al paciente puesto que contienen los mensajes de las voces críticas. Esta facilitación puede encaminarse a la identificación de los deberías del paciente.

De forma paulatina, la persona puede tomar una conciencia vaga del problema de la autocrítica (APES 2. Reconocimiento vago/surgimiento), aunque no logre identificarlo de manera clara. Es probable que la persona refiera dos partes contrapuestas con un pero o por otro lado... (Greenberg et al., 1996). También cabe la posibilidad de que la persona comience a atribuir el aspecto crítico de la escisión en otras personas, es decir, como si fueran otros quienes realizan esta evaluación o autocoerción.

Para llegar a este nivel, es importante que el terapeuta haya centrado su atención en dar luz tanto a las partes críticas como al efecto que dichas partes tienen en la voz que experiencia. Para ello, en primer lugar el terapeuta clarifica verbalizándole al paciente la existencia de los dos aspectos opuestos de la personalidad ("hay una parte de ti que quiere esto pero otra parte que le asusta").

Si se han detectado autoevaluaciones que el paciente atribuye a otros, se puede pedir que represente las críticas (en contenido y forma) de los demás para comenzar a identificar su fuente interna. Conforme estas supuestas críticas de los otros se van matizando, puede que el paciente perciba que parten de él. Si esto no sucede, se puede plantear el trabajo como un problema interpersonal.

Con este grado de conciencia es esperable que la persona experimente dolor psicológico, ya sea conforme se está trabajando en el contexto de la terapia o porque este sea el momento en el que la persona decida iniciar un proceso terapéutico.

Progresivamente, a través de las intervenciones del terapeuta, la persona puede diferenciar la aparición de dos lados en conflicto (APES 3. Enunciar el problema/clarificación). En este punto, se puede comenzar a separar una voz que contiene una serie de demandas que hacen sufrir a otra voz que expresa una serie de necesidades y deseos que no están siendo atendidos. Sin embargo, la definición en este punto aún es confusa. En la medida en el que se ha facilitado la identificación de esta situación intrapersonal, la discordia entre ambas voces permanece más tiempo en la conciencia. En esta fase, el afecto continúa siendo negativo aunque resulta manejable.

Con el fin de favorecer un avance en la clarificación del conflicto, el terapeuta puede explicar la finalidad de la tarea de las dos sillas y estructurarla. Es decir, el terapeuta va a proponer una tarea que implica un proceso de identificación y clarificación dinámico de dos aspectos de la persona que se encuentran contrapuestos. Conforme las voces disonantes fueron identificadas y con el objetivo de lograr la separación de las dos, el terapeuta puede proponer que las voces se dirijan frases entre ellas, expresando sentimientos y deseos, que comenzarán a definir críticas generalizadas como no valgo para nada. Cabe destacar que, generalmente, el terapeuta pide al paciente que sea la voz crítica la que empiece haciendo sentir al experienciador culpable o criticado; parece que esta es una mejor forma de activar el esquema emocional que conforma la escisión autocrítica.

Una vez realizado este trabajo, se profundiza en la comprensión de cada voz (APES 4. Comprensión/ insight). Toda esta experiencia conflictiva se puede reordenar en una reformulación que viene dada de la compresión de las voces y del establecimiento de vínculos (puentes de significado) en cada una de ellas.

Para la terapia focalizada en la emoción, la comprensión de las voces y el establecimiento de puentes de significados es posible cuando se accede al dolor nuclear de la voz que experiencia la crítica. Esto implica el acceder a la emoción primaria, más profunda, y la necesidad subyacente, que puede reflejar la vergüenza, el miedo o el sentimiento de soledad al recibir la crítica. Al producirse la activación de la crítica se produce la activación emocional (elevación del aroussal) y la emoción primaria es dirigida a la crítica. Como explicamos a continuación, la expresión del dolor del experienciador es el elemento que puede permitir su suavización o si no, el desarrollo en el experienciador de estrategias de protección de la voz crítica mediante la transformación emocional.

A tenor de esto, en este punto de la intervención el terapeuta solicita al paciente que atienda a cada uno de las voces para que hablen con más precisión de su propia experiencia, y la dirija hacia el otro aspecto contrapuesto. El ejercicio de cambio de sillas favorece la separación de las voces, el insight y a su vez el contacto real. 
Tal y como lo entendemos, es en este momento en el que pueden surgir los puentes de significado entre las voces, porque se fomenta la expresión de sentimientos y deseos entre las sillas, generando un diálogo que puede tomar vida propia, es decir, activa todo aquello que está registrado en el rastro de la experiencia. Además, cuando el terapeuta anima a hablar desde yo y tú, el reconocimiento de la experiencia (principalmente emocional) se ve potenciado. En la terapia focalizada en la emoción, el punto de inflexión para movilizar el cambio interno se da cuando los puentes de significado permiten al crítico empatizar con el dolor y la necesidad subyacente del experienciador.

En este juego de roles emergen las críticas que previamente no estaban definidas, fácilmente podrían permanecer mezcladas en un monto de malestar. Conforme las críticas se vuelven más precisas, las reacciones de la voz del experienciador también pasan de un conjunto de sentimientos a emociones primarias que están más definidas, como la tristeza y la soledad. Posteriormente, conforme el experienciador se expresa pueden activarse sentimientos de enfado por contener una serie de necesidades que no son escuchadas. Esto permite pasar del sentimiento de malestar y culpa a una orientación hacia sí mismo más profunda. Por tanto, a pesar de lo desagradable del reconocimiento de aspectos dolorosos y el rechazo hacia uno mismo, las personas pueden sentir curiosidad y gratificación al reconocerse en aspectos negados, evitados o no atendidos.

En esta etapa, que implica un trabajo de varias sesiones de terapia, el afecto puede ser oscilante, con activación del afecto negativo pero en la medida que se accede al afecto negativo primario, se puede acceder a un afecto más adaptativo (puede ser un enfado asertivo hacia la autocrítica, un incremento en la capacidad de autoconsuelo o la conexión con un sentimiento de tristeza o duelo). Según propone la teoría de la asimilación, esta mayor conexión entre voces puede favorecer la suavización del malestar y el logro de un humor más positivo; a nosotros nos parece importante señalar que un humor positivo no tiene porqué ser emociones positivas como la felicidad, un incremento del bienestar en el sentido de un incremento de la coherencia y comprensión interna, más allá de las emociones prominentes. Por ejemplo, uno puede encontrar mayor bienestar cuando el sentimiento que se despierta es de enfado asertivo cuando se siente menoscabado por parte de otra persona, el enfado no es una emoción "positiva" pero sí permite una sensación de bienestar con uno mismo.

Así, al avanzar en la formación de este esquema de funcionamiento intrapersonal donde el problema se torna más comprensible, las personas se pueden comprometer en un mayor trabajo con el problema y su resolución (APES 5. Aplicación/elaboración). Es decir, planteada esta separación, explorados los conjuntos de esquemas, el paciente ahonda en los valores y normas personales (organísmicos), no los que contiene de manera rígida la voz crítica. Al mismo tiempo, la voz crítica comienza a suavizarse y a atender a estas necesidades de la voz del experienciador.

Esto permite también que la voz del experienciador adopte una posición más abierta hacia las preocupaciones que encarna la voz crítica. En otras palabras, también puede llegar a entender la funcionalidad de esta voz crítica. El afecto continuará recobrando un valor más positivo, disminuirá la confusión e impulsará la toma de decisiones, sean del tipo que sean.

Posteriormente, se llega a una solución del problema (APES 6. Solución del problema). Existe una sensación satisfactoria cuando se llega a una resolución, la cual puede variar en función de la persona. Es decir, puede existir una aceptación total y de las necesidades organísmicas pero también se puede llegar a una resolución que pasa por la negociación e integración de ambas partes. En cambio, aunque este es un resultado menos frecuente, la persona podría proponerse rechazar sus necesidades organísmicas en pro de un ideal (Greenberg et al., 1996).

En este punto, los puentes de significados son fuertes y se pueden dirigir con mayor facilidad entre las voces, recuperando los recursos y estrategias que cada una de ellas contienen. En la medida en que el paciente se siente menos encorsetado, el bienestar psicológico aumenta.

APES describe una séptima etapa (APES 7. Dominio), que señala cómo el paciente emplea con éxito nuevas soluciones. En realidad, esto surge de manera natural y progresiva en la medida que la persona logra ir resolviendo la disociación entre las partes. En esta fase, sí se puede discernir que existe una generalización a más aspectos de la relación intrapersonal, así como a diferentes contextos, más allá del contexto de la terapia. 


\section{Referencias}

Brinegar, M. G., Salvi, L. M., Stiles, W. B. y Greenberg, L. S. (2006). Building a meaning bridge: Therapeutic progress from problem formulation to understanding. Journal of Counseling Psychology, 53, 165-180. https://doi.org/10.1037/0022-0167.53.2.165

Caro, I. (2003). La resolución de experiencias problemáticas en la terapia lingüística de evaluación según el modelo de asimilación: El análisis de Silvia (II). Boletín de Psicología, 79, 59-84.

Cooper, M., Mearns, D., Stiles, W. B., Warner, M. y Elliott, R. (2004). Developing Self-Pluralistic Perspectives Within the Person-Centered and Experiential Approaches: A round-table dialogue/Entwicklung selbst-pluralistischer Perspektiven in den personzentrierten und experienziellen Ansätzen: Ein Gespräch am runden Tisch/Desarrollando las perspectivas pluralistas del self dentro de los enfoques centrados en la persona y experienciales: un diálogo en una mesa redonda. Person-Centered \& Experiential Psychotherapies, 3, 176191. https://doi.org/10.1080/14779757.2004.9688345

Elliott, R., Watson, J. C., Goldman, R. N. y Greenberg, L. S. (2004). Learning Emotion-Focused Therapy: The process-experiential approach to change. Washington, D.C.: American Psychological Association. https:// doi.org/10.1037/10725-000

Greenberg, L. S., Rice, L. N. y Elliott, R. (1996). Facilitando el cambio emocional: El proceso terapéutico punto a punto. Barcelona, España: Paidós.

Hermans, H. J. (2004). The dialogical self: Between exchange and power. En J. M. Hermans y G. Dimaggio (Eds.), The Dialogical Self in Psychotherapy (pp. 29-44). Nueva York, NY: Bruner - Routledge. https://doi. org/10.4324/9780203314616

Honos-Webb, L. y Stiles, W. B. (1998). Reformulation of assimilation analysis in terms of voices. Psychotherapy: Theory, Research, Practice, Training, 35(1), 23. https://doi.org/10.1037/h0087682

Honos-Webb, L., Stiles, W., Greenberg, L. y Goldman, R. (1998). Assimilation analysis of process-experiential psychotherapy: A comparison of two cases. Psychotherapy Research, 8, 264-286. https://doi.org/10.108 0/10503309812331332387

Leiman, M. (2002). Toward semiotic dialogism: The role of sign mediation in the dialogical self. Theory \& Psychology, 12, 221-235. https://doi.org/10.1177/0959354302012002631

Mearns, D. y Thorne, B. (2003). La terapia centrada en la persona hoy: nuevos avances en la teoría y en la práctica. Bilbao, España: Desclée de Brouwer.

Mosher, J. K., Goldsmith, J. Z., Stiles, W. B. y Greenberg, L. S. (2008). Assimilation of Two Critic Voices in a Centered Therapy for Depression. Person-Centered and Experiential Psychotherapies 7(1), 1-19. https:// doi.org/10.1080/14779757.2008.9688449

Osatuke, K., Gray, M.A., Glick, M. J ., Stiles, W. B.y Barkham, M. (2004). Hearing voices: Methodological issues in measuring internal multiplicity. En H.H. Hermans y G. Dimaggio (Eds.), The Dialogical Selfin Psychotherapy (pp. 237-254). Nueva York, NY: Brunner-Routledge. https://doi.org/10.4324/9780203314616 chapter 15

Osatuke, K., Humphreys, C. L., Glick, M. J., Graff-Reed, R. L., McKenzie Mack, L. T. y Stiles, W. B. (2005). Vocal manifestations of internal multiplicity: Mary's voices. Psychology and Psychotherapy: Theory, research and practice, 78, 21-44. https://doi.org/10.1348/147608304X22364

Ramírez, J. A. (1998). Psicodrama: Teoría y Práctica. Bilbao, España: Desclée De Brouwer.

Ribeiro, A. P., Bento, T., Salgado, J., Stiles, W. B. y Gonçalves, M. M. (2011). A dynamic look at narrative change in psychotherapy: A case study tracking innovative moments and protonarratives using state space grids. Psychotherapy Research, 21(1), 54-69.

Rogers, C. R. (1959). A theory of therapy, personality, and interpersonal relationships as developed by the client-centered framework. En S. Koch (Ed.), Psychology: A study of a science: Volume III. Formulations of a person and the social context (pp. 184-256). Nueva York, NY: McGraw-Hill.

Rowan, J. (1990). Subpersonalities: The people inside us. Londres, Reino Unido: Routledge.

Stiles, W. B. (1992). Assimilation in der Klientenzentrierten Psychotherapie [Assimilation in client- centered therapy]. En R. Sachse, G. Lietaer, y W. B. Stiles (Eds.), Neue Handlungskonzepte der Klientenzentrierten 
Psychotherapie (pp. 39-47). Heidelberg, Alemania: Roland Asanger Verlag.

Stiles, W. B. (1997). Signs and voices: Joining a conversation in progress. British Journal of Medical Psychology, 70, 169-176. https://doi.org/10.1111/j.2044-8341.1997.tb01896.x

Stiles, W. B. (1999). Signs and voices in psychotherapy. Psychotherapy Research, 9, 1-21. https://doi.org/10. 1080/10503309912331332561

Stiles, W. B. (2002). Assimilation of problematic experiences. En J. C. Norcross (Ed.), Psychotherapy Relationships that Work: Therapist Contributions and Responsiveness to Patients (pp. 357-365). Nueva York: Oxford University Press.

Stiles, W. B. (2011). Coming to terms. Psychotherapy Research, 21, 367-384. https://doi.org/10.1080/105033 07.2011 .582186

Stiles, W. B., Honos-Webb, L. y Lani, J. A. (1999). Some functions of narrative in the assimilation of problematic experiences. Journal of Clinical Psychology, 55, 1213-1226. https://doi.org/10.1002/(SICI)1097-4679 (199910)55:10<1213::AID-JCLP4>3.0.CO:2-1

Stiles, W. B., Leiman, M., Shapiro, D. A., Hardy, G. E., Barkham, M., Detert, N. B. y Llewelyn, S. P. (2006). What does the first exchange tell? Dialogical sequence analysis and assimilation in very brief therapy. Psychotherapy Research, 16, 408-421. https://doi.org/10.1080/10503300500288829

Stiles, W. B., Morrison, L. A., Haw, S. K., Harper, H., Shapiro, D. A. y Firth-Cozens, J. (1991). Longitudinal study of assimilation in exploratory psychotherapy. Psychotherapy: Theory, Research, Practice, Training, 28(2), 195. https://doi.org/10.1037/0033-3204.28.2.195

Stiles, W. B., Osatuke, K., Glick, M. J. y Mackay, H. C. (2004). Encounters between internal voices generate emotion: An elaboration of the assimilation model. En H. H. Hermans y G. Dimaggio (Eds.), The Dialogical Self in Psychotherapy (pp. 91-107). Nueva York; NY: Brunner-Routledge. https://doi. org/10.4324/9780203314616 chapter 6 